\title{
Colisión de Derechos derivada de la pandemia por COVID-19 ante el posible aplazamiento de Elecciones en México
}

\author{
Collision of Rights derived from the COVID-19 pandemic before the \\ possible postponement of Elections in Mexico
}

Juan MANuel Vázquez Barajas ${ }^{1}$

$0^{\circ}$ IUs Comitiãlis / Año 3, Número 6 / julio - diciembre 2020 / pp. 286-305 / ISSN: 2594-1356 Recepción: 29 de julio de 2020 / Aceptación: 03 de noviembre de 2020

Resumen: Frente al desarrollo de la pandemia, México ha optado por reprogramar procesos electorales. Llama la atención el caso especial de Coahuila e Hidalgo, donde el Instituto Nacional Electoral hizo uso de la facultad de atracción, en la que determinó suspender los procesos electorales locales en esas entidades. La realización o no de comicios electorales, trae a la mesa un debate ante la no progresividad del derecho humano a la salud y el derecho al voto, situación que, de prolongarse podría suscitar una colisión de derechos.

Palabras clave: Elecciones, salud, COVID-19, pandemia, progresividad.

Abstract: Faced with the development of the pandemic, Mexico has chosen to reschedule electoral processes. The special case of Coahuila and Hidalgo draws attention, where the National Electoral Institute made use of the power of attraction, in which it determined to suspend the local electoral processes in those entities. The realization or not of electoral elections, brings to the table a debate regarding the non-progressivity of the human right to health and the right to vote, a situation that, if prolonged, could lead to a collision of rights.

Key words: Elections, health, COVID-19, pandemic, progressiveness.

${ }^{1}$ Doctorando en Derecho, por la Universidad Cristóbal Colón. Doctorando en Derecho Electoral, por la Escuela Judicial Electoral del Tribunal Electoral del Poder Judicial de la Federación. Docente de licenciatura en materias afines al derecho; en las universidades Cristóbal Colón, Universidad de Xalapa y Universidad del Valle de México. Consejero Electoral del Organismo Público Local Electoral del Estado de Veracruz. México 


\section{INTRODUCCIÓN}

La actual emergencia sanitaria que atraviesa el país ha trastocado de manera importante la vida y la cotidianidad de la ciudadanía mexicana, esto a tal grado que se han modificado los patrones de convivencia, laborales, sociales, económicos y, para el caso que ahora se estudiará, en la manera de llevar a cabo los procesos electorales en nuestro país.

Ante tal panorama, el Consejo General del Instituto Nacional Electoral (INE) ha emitido un acuerdo que determinó la suspensión de los procesos electorales en las entidades de Hidalgo y Coahuila. Este acuerdo trae al debate la ponderación del derecho humano que debe prevalecer: la salud o el voto.

Esta emergencia sanitaria ha tenido entre sus diversos efectos, la publicación de exhortos para la suspensión de actividades multitudinarias o que impliquen situaciones de riesgo para la salud de la población, a grandes rasgos, esto llevó al Consejo General del INE a reprogramar la realización de procesos electorales locales y pausar las actividades presenciales del propio instituto.

Todo este escenario, que no cuenta con precedente alguno, ha llevado a una posible colisión de derechos: ¿qué es más importante, el derecho a un estado óptimo de salud o el derecho de la ciudadanía a votar y ser votado? ¿qué sucede en el caso de que los tiempos de vigencia de los cargos públicos prescriban y aún no sea posible la realización de elecciones?

Esta colisión de derechos se torna compleja, pues la configuración del sistema electoral mexicano requiere la congregación multitudinaria en las casillas electorales, contexto que genera riesgos de contagio y podría poner en una situación todavía más compleja al sistema de salud pública en los contextos de la pandemia.

Indirectamente, esta pandemia, y sus complicaciones, han vulnerado el principio de progresividad de derechos, cuando se relaciona el derecho al voto con el de la salud, pues la realización de elecciones podría vulnerar el estado de salud de la ciudadanía y, por otra parte, las acciones para salvaguardar a la población, pueden llegar a atentar contra el derecho al sufragio, lo que podría representar un retroceso en materia electoral, de participación ciudadana y de resultados electorales.

Esta posible colisión de derechos humanos hace evidente la necesidad de flexibilizar el modelo electoral mexicano, pues los rezagos en el sistema electoral se ven reflejados en la incapacidad de adaptación de las instituciones electorales ante contingencias como la que se vive en la actualidad. 
Este artículo constituye una aproximación a la propuesta de un estudio de caso, en una situación de emergencia en México, en el año 2020, específicamente en el desarrollo de procesos electorales locales, focalizando la atención en los casos específicos de Hidalgo y Coahuila.

Pudiera parecer que este texto perderá vigencia dentro de uno o dos años una vez que la emergencia sanitaria haya pasado, pero se considera este documento como un punto de partida para reflexionar en torno al tema en futuros panoramas emergentes de similares condiciones.

Si bien, este es un acercamiento a un estudio de caso, pues se considera apropiado para temas que son considerados relativamente nuevos, donde sea necesario “comprender las dinámicas presentes en contextos singulares”, el ensayo contribuirá al análisis de la realización de elecciones en situaciones de contingencia. Cabe mencionar que cuando esta metodología se aplica de manera rigurosa, permite explorar de manera más profunda y obtener un conocimiento más amplio sobre los fenómenos estudiados (Carazo, 2006, pág. 174).

En este ensayo, se analizarán las consecuencias de la pandemia en el ámbito electoral, principalmente los casos de aplazamiento de elecciones locales como consecuencia del desarrollo de la pandemia por COVID-19 en nuestro país, así como las posibles repercusiones en materia de derechos humanos, especialmente en el principio de progresividad y una incipiente colisión de derechos entre el derecho a la salud y el derecho a elegir a nuestros gobernantes.

\section{ANTECEDENTES}

En la vasta familia de coronavirus, algunos pueden ocasionar enfermedades que van desde una simple gripe, hasta el Síndrome Respiratorio Agudo Severo (SARS). El tipo de coronavirus causante de la pandemia que ahora nos aqueja, ha sido descubierto recientemente y ocasiona la llamada enfermedad por coronavirus COVID-19.

La Organización Mundial de la Salud puntualiza que esta enfermedad era desconocida hasta el primer brote que se dio en Wuhan, China, el pasado diciembre de 2019, se considera que la COVID-19 es una pandemia ${ }^{2}$ que ha tenido repercusiones en diversos países del mundo.

La enfermedad por COVID-19 es sumamente contagiosa e infecciosa ya que puede llegar a afectar tanto a personas menores de edad como adultos en plenitud. Se propaga fácilmente al tener contacto con objetos o superficies infectadas por el virus y posteriormente llevarse las manos a la boca, ojos o nariz (Instituto Nacional Electoral, 2020, págs. 1-15).

\footnotetext{
${ }^{2}$ La OMS define a una pandemia como la propagación mundial de una nueva enfermedad. (Organización Mundial de la Salud, 2020)
} 
La principal vía de contagio de esta enfermedad, es el contacto con una persona infectada por el virus por medio de gotículas emitidas al toser o estornudar de una persona enferma a una sana. Entre las recomendaciones emitidas por la OMS para la prevención de contagios masivos se encuentra mantener un metro de distancia con los demás, mantener lo más limpio posible el entorno inmediato, no tocarse la cara y lavar frecuentemente las manos (Organización Mundial de la Salud, 2020).

Las medidas anteriormente mencionadas son uno de los impedimentos para la realización convencional de procesos electorales, pues la aglomeración de personas y la dificultad de mantener una correcta rutina de lavado de manos, hace prácticamente imposible respetar las medidas sanitarias sin poner en riesgo a las personas integrantes de los consejos y las mesas de casillas, así como a la ciudadanía en general. Además, que todos los actos preparatorios implican reuniones de muchas personas en espacios cerrados.

\section{SITUACIÓN ACTUAL INTERNACIONAL Y NACIONAL DE LA PANDEMIA POR COVID-19}

La Organización Mundial de la Salud declaró, con fecha 11 de marzo del 2020, que el brote del virus SARS-CoV2, mejor conocido como COVID-19, se consideraría como una pandemia, pues este nuevo síndrome se incrementa de manera importante en los países que habían confirmado casos. Esto constituye una emergencia de salud pública de importancia internacional por lo que fueron emitidas una serie de recomendaciones para la mitigación de su impacto (Instituto Nacional Electoral, 2020, págs. 1-51).

A la fecha de la realización del presente artículo, se contaba con el reporte de más de catorce millones de casos confirmados y más de seiscientas mil personas fallecidas alrededor del mundo, siendo el continente americano donde más casos nuevos se han presentado $(117,400)$. Entre los datos de la OMS figura que, hasta la fecha, se han reportado casos en 215 países (Secretaría de Salud y Asistencia, 2020).

En México, han sido confirmados más de trescientos mil casos y se han presentado más de cuarenta mil defunciones; las cinco entidades federativas que mayor número de casos acumulados (incidencia) por lugar de residencia, son la Ciudad de México, Estado de México, Tabasco, Veracruz y Puebla, en los mencionados estados se conjunta el $46 \%$ de todos los casos registrados en México, todo esto de acuerdo a información de la Secretaría de Salud y Asistencia. Para el caso que nos ocupa, Hidalgo y Chiapas, se encuentran ubicadas en la posición 20 y 21 respectivamente.

La Ciudad de México, Estado de México, Nuevo León y Guanajuato, presentan más de tres mil casos activos estimados ${ }^{3}$, en conjunto, se calcula que estas cuatro entidades concentran casi cincuenta mil casos estimados (Secretaría de Salud y Asistencia, 2020).

\footnotetext{
${ }^{3}$ Esto se entiende como los casos activos más sospechosos, cuya fecha de inicio fue en los últimos 14 días por
} el índice de positividad, por entidad y semana epidemiológica. (Secretaría de Salud y Asistencia, 2020) 


\section{APLAZAMIENTO DE ELECCIONES LOCALES EN MÉXICO}

Con fecha 17 de marzo del presente año, la Junta General Ejecutiva del Instituto Nacional Electoral emitió un acuerdo por el que fueron establecidas medidas preventivas y de actuación, con motivo de la mencionada pandemia.

La Junta General Ejecutiva del INE emitió este acuerdo, pues dentro de sus atribuciones se encuentra dictar las medidas administrativas necesarias para dotar de certeza a las diversas áreas que conforman al Instituto para que se garantice la continuidad en sus trabajos y, por otro lado, sean aseguradas las condiciones de óptima seguridad e higiene en sus espacios físicos y en los módulos en los que la ciudadanía acude a realizar diversos trámites (Instituto Nacional Electoral, 2020).

El acuerdo, ya mencionado, puntualizó que ante la velocidad de transmisión del virus, el INE buscó adoptar un enfoque integral que lleve a un desempeño informado y responsable donde se coordinen los esfuerzos de la autoridad sanitaria y los del Instituto.

En ese momento, se estableció que se debía continuar con el desarrollo de funciones esenciales y con las actividades tendientes a la realización de los Procesos Electorales Locales (Coahuila e Hidalgo). Para el caso de los procesos locales en Coahuila e Hidalgo se instruyó en el acuerdo, que tanto supervisores, como CAE suspenderían las tareas de capacitación, se realizaría un ajuste a los periodos relativos a la capacitación, se suspenderían los eventos públicos relacionados con la promoción de la participación ciudadana y lo relacionado con la Estrategia Nacional de Cultura Cívica 2017-2023 (Instituto Nacional Electoral, 2020).

Para el caso del Proceso Electoral Local en el estado de Coahuila, el Poder Ejecutivo, emitió un decreto por el cual fueron establecidas medidas para el control del contagio del COVID-19 en la entidad, pues fue declarado estado de emergencia ante un inminente desastre sanitario, por lo que fueron suspendidos eventos masivos del 19 al 31 de marzo del año 2020 (Instituto Nacional Electoral, 2020).

El Poder Ejecutivo de Hidalgo, publicó el 19 de marzo un acuerdo en el que se establecen las medidas para la prevención de la enfermedad infecciosa mediante la suspensión de eventos públicos de toda la administración pública estatal (Instituto Nacional Electoral, 2020).

Mediante el acuerdo INE/CG82/2020, fueron suspendidos los plazos y términos relativos a actividades relacionadas con la función electoral y que son responsabilidad del INE, hasta que la pandemia fuese contenida. En este documento, el Consejo General, especificó que los procesos electorales locales se llevarían a cabo siempre y cuando no se vulnere el estado de salud de la ciudadanía, más no se considerarían como suspendidos. (Instituto Nacional Electoral, 2020). 
El primero de abril del 2020, en sesión extraordinaria del Consejo General del INE, fue aprobada la resolución por la que se ejerce la faculta de atracción con la finalidad de suspender temporalmente el desarrollo de los procesos electorales locales en los estados de Coahuila e Hidalgo, esto con motivo de la pandemia COVID-19, generada por el virus SARS-CoV2.

En este acuerdo, se hace mención del oficio IEEH/PRESIDENCIA/289/2020 en el que la consejera presidenta del instituto electoral del estado de Hidalgo, hace del conocimiento del Consejo General del INE, la existencia de diversas solicitudes por parte de representaciones de partidos relacionadas con la suspensión del Proceso Electoral (Instituto Nacional Electoral, 2020).

El pasado 16 de julio del 2020, el Instituto Nacional Electoral y el Instituto Estatal Electoral de Hidalgo sostuvieron una reunión de trabajo para el establecimiento de criterios para la reanudación del PEL 2019-2020, esta reanudación de actividades conlleva la implementación de medidas de sanidad en las casillas para que a la ciudadanía le sea posible votar sin poner en riesgo su salud. En la mencionada reunión se propuso como fecha probable para llevar a cabo la Jornada Electoral el próximo domingo 18 de octubre; esto siempre y cuando los semáforos sanitarios lo permitan (Instituto Nacional Electoral, 2020).

Cabe mencionar que en el decreto que ordena la inmediata suspensión de actividades "no esenciales" no se considera como esencial a la función electoral. Se puntualiza que el regreso será escalonado y regionalizado a las actividades laborales, económicas y sociales de toda la población mexicana (Diario Oficial de la Federación, 2020).

Por su parte la OEA, ha emitido una guía para la organización de elecciones en los estados miembros en tiempos de pandemia donde enfatiza a las naciones la importancia de proyectar alternativas que velen por la democracia en medio del desarrollo de una pandemia, esto con la finalidad de que no se vea vulnerada la legitimidad del origen de las y los gobernantes electos.

Este manual puntualiza que todas las medidas sanitarias y de prevención no garantizan un riesgo igual a cero de contagio, la realización de elecciones podría repuntar los contagios, por lo que, en la mayoría de los casos, será necesario redefinir todos los protocolos electorales

La OEA menciona la importancia de no posponer de manera indefinida la realización de las jornadas electorales, pues "la democracia no debe caer en la incertidumbre, sino, al contrario, debe reafirmarse a través de señales y acciones concretas" (Organización de los Estados Americanos, 2020, págs. 9-220).

Esta organización establece diversas pautas para la realización de elecciones, más allá de las medidas sanitarias, tales como priorizar el uso de herramientas digitales y tecnológicas, implementar normativas para sancionar la violencia política que se presenta en redes sociales, cuidar de la ciudadanía en situación de vulnerabilidad, así como el cuidado de datos personales. 


\section{PREVISIONES EN LA CONSTITUCIÓN POLÍTICA DE LOS ESTADOS UNIDOS MEXICANOS}

No existe una pauta clara en la constitución mexicana respecto del actuar de las autoridades electorales ante el desarrollo de procesos electorales federales o locales en medio de una emergencia sanitaria.

Lo que si se establece con claridad, en el artículo 116 constitucional es que, la duración de las campañas electorales tendrá una duración de entre 30 y 60 días para las diputaciones locales o de ayuntamientos. Por su parte, las precampañas no podrán durar más de dos terceras partes de las campañas; la jornada electoral tendrá lugar el primer domingo de junio del año correspondiente.

El artículo 73, de la Constitución Política de los Estados Unidos Mexicanos estipula que, en caso de peligro de invasión de enfermedades en el país, la Secretaría de Salud, estará en la obligación de dictar las medidas preventivas indispensables, estas medidas serán acatadas por las autoridades administrativas mexicanas. (Cámara de Diputados del H. Congreso de la Unión, 2020)

\section{ATRIBUCIONES DEL INE}

Como ya se mencionó anteriormente, las leyes y normativas electorales no consideran de manera expresa la actuación de las autoridades electorales ante una emergencia sanitaria, por lo que fue necesario emitir acuerdos y resoluciones para el diseño de un plan de acción ante los procesos electorales locales próximos en las entidades de Coahuila e Hidalgo.

Quienes integran el Consejo General del INE, estimaron que, como rector del sistema nacional electoral, la decisión de modificar los plazos para la realización de procesos electorales le corresponde a este consejo por mandato constitucional. Consideraron que esta resolución priorizaba el ejercicio del derecho humano a la salud, poniendo en pausa el derecho al voto (Instituto Nacional Electoral, 2020).

La postergación de elecciones por motivo de la pandemia del COVID-19 no es exclusivo de nuestro país, el ya citado acuerdo INE/083 hace mención de un total de 37 países, donde fueron modificadas las fechas de realización de procesos electorales como parte de las medidas emergentes para controlar la epidemia.

En el acuerdo por el cual se determina la resolución de la solicitud de la facultad de atracción para la suspensión temporal del desarrollo de los procesos electorales locales en Coahuila e Hidalgo, por motivo de la pandemia por COVID-19; se considera 
como interés superior ${ }^{4}$ el derecho a la salud de la ciudadanía mexicana (Instituto Nacional Electoral, 2020).

En el informe presentado por la Secretaría Ejecutiva del INE, el día 19 de junio del 2020, se menciona que respecto al desarrollo de los procesos electorales locales en Coahuila e Hidalgo, "se han realizado trabajos de planeación que consideren los posibles nuevos plazos y fechas en que se desarrollarán las fases y etapas pendientes" (Instituto Nacional Electoral, 2020).

La Secretaría Ejecutiva presentó tres propuestas para la actualización de los calendarios, tomando en cuenta que se requieren 70 días para todos los actos previos a la jornada electoral; el escenario uno propone como día de la jornada electoral, el 30 de agosto, el cómputo para la asignación de diputaciones o regidurías de Representación Proporcional, el 6 de septiembre para el caso de Coahuila y una vez que se resuelvan medios de impugnación en el caso de Hidalgo, siendo el 22 de junio la fecha límite para el reinicio de actividades el PEL.

Por su parte, el escenario dos, establece como fecha límite para retomar actividades relacionadas por el PEL el día 29 de julio, la jornada se realizaría el 6 de septiembre y el cómputo para la asignación de diputaciones o regidurías de Representación Proporcional el 13 de septiembre del 2020; el escenario tres, que, para los tiempos estimados, era el más viable, plantea como fecha de la jornada electoral, el 20 de septiembre, la fecha límite para el reinicio de actividades del PEL fue el pasado 12 de julio y el 27 de septiembre el cómputo para la asignación de diputaciones y regidurías de Representación Proporcional para el caso de Coahuila y una vez que se resuelvan los medios de impugnación en el caso de Hidalgo. (Instituto Nacional Electoral, 2020)

Como es posible notar, el desarrollo de la pandemia por COVID-19 ha representado un reto en materia electoral, en especial, la realización de procesos electorales. Si bien, se han considerado implementar diversas medidas, por ejemplo, los mecanismos propuestos por el INE o el Instituto Electoral de Coahuila5, más no se cuenta con la certeza de que sean efectivos para en la prevención de contagios.

\section{PLANTEAMIENTO DEL PROBLEMA: PROBABLES RIESGOS SANITARIOS ANTE EL DESARROLLO USUAL DE PROCESOS ELECTORALES LOCALES}

La norma electoral mexicana requiere que los procesos de votación y cómputo sigan procedimientos presenciales que, dadas las condiciones de la crisis sanitaria actual,

\footnotetext{
${ }^{4}$ El artículo 124 de la LGIPE. "Se considera que una cuestión es trascendente cuando la naturaleza intrínseca del asunto permita que éste revista in interés superlativo reflejado en la gravedad del tema, es decir, en la posible afectación o alteración del desarrollo del proceso electoral o de los principios de la función electoral” (Cámara de Diputados del H. Congreso de la Unión, 2020)

${ }^{5}$ Se recomienda revisar Sesión Ordinaria del Consejo General del Instituto Electoral de Coahuila del 30 de junio, 2020. Liga electrónica: https://www.youtube.com/watch?v=5wH2zgbBy4A
} 
presentan riesgos significativos para las personas involucradas. Cada una de las etapas contiene riesgos, dado que implican la visita de capacitadores electorales a diversos domicilios, la congregación de votantes en casilla, y el trabajo multitudinario en los centros de cómputo post jornada electoral.

Si se analiza con detenimiento, la manera en que se realizan las elecciones de manera "tradicional" implica una gran cantidad de riesgos sanitarios, las casillas son zonas de riesgo ante la aglomeración de personas, los instrumentos para la votación son utilizados por muchas personas y el riesgo aumenta en las salas de sesiones, pues son espacios generalmente cerrados.

La situación de salud que actualmente vivimos podría afectar de manera inesperada los procesos electorales, pues nos hay seguridad de que la ciudadanía acepte ser funcionaria o funcionario de casilla por el temor de contagio e incluso, podría presentarse el caso de que tampoco las personas acepten ser capacitadoras electorales o presten sus casas para la instalación de casillas, además del inminente riesgo de aumento en el abstencionismo, pues las personas no acudirán a votar por temor al contagio.

Es evidente que continuar realizando elecciones de manera convencional implica poner en riesgo tanto a la ciudadanía como al funcionariado, esto pone de frente el reto de pensar elecciones más seguras, económicas e higiénicas.

\section{POSIBLES CONSECUENCIAS DEL APLAZAMIENTO O SUSPENSIÓN DE PROCESOS ELECTORALES EN MÉXICO}

Es posible vislumbrar dos panoramas ante la realización o no de los procesos electorales, el primero, es posponerlos hasta que el riesgo de contagio disminuya, cosa que podría llevar a que los cargos públicos a elegir terminen sus periodos de vigencia y esto lleve a las entidades a hacer uso de sus atribuciones desde el Congreso Local para elegir representaciones interinas. El aspecto de los cargos quedaría subsanado, pero la ciudadanía dejaría en pausa el ejercicio de su derecho a votar y ser votados indefinidamente.

El segundo panorama es la realización de elecciones aún en medio de la pandemia, esto contravendría el derecho a la salud y el bienestar de la ciudadanía a costa del pleno cumplimiento del derecho a votar y ser votados.

El propio INE se ha visto orillado a ponderar entre ambos escenarios, esto deja a una autoridad administrativa con la responsabilidad de acordar acerca de estas situaciones emergentes dado que las normas existentes no muestran rasgos de flexibilidad y lleva a la limitación para garantizar derechos político electorales en contingencias similares a las que ahora vivimos. Cabe mencionar que, a la fecha, el Consejo General de INE no ha emitido un nuevo acuerdo en el que indique la reanudación del 
proceso electoral en las dos entidades federativas anteriormente mencionadas.

Ante un panorama de emergencia sanitaria, es posible notar que pensar las elecciones de manera "tradicional" con algunos ajustes o medidas emergentes, no reducirán el riesgo sanitario al que se podría exponer la ciudadanía, es necesario pensar más allá y hacer uso de todas las herramientas disponibles para que ningún derecho humano sea vulnerado.

\section{NO PROGRESIVIDAD DE DERECHOS HUMANOS ANTE LA SUSPENSIÓN O APLAZAMIENTO DE PROCESOS ELECTORALES LOCALES}

Otro aspecto del problema son todas las medidas emergentes que se han implementado a causa de pandemia, pues para el caso del ámbito electoral, esto representa un retroceso en el principio de progresividad en los derechos humanos.

La Comisión Nacional de Derechos Humanos puntualiza que el principio de progresividad es el "gradual progreso para lograr su pleno cumplimiento, es decir, que para el cumplimiento de ciertos derechos se requiera la toma de medidas a corto, mediano y largo plazo, pero procediendo lo más expedita y eficazmente posible" (Comisión Nacional de Derechos Humanos, 2018).

Este principio, se relaciona más con los derechos sociales, específicamente el derecho a la salud, pero también se puede aplicar a los derechos civiles y políticos, debe ser una prioridad de las instituciones y los estados que estos derechos se satisfagan en cada momento.

Por su parte, la Sala Superior del Tribunal Electoral del Poder Judicial de la Federación, en el año 2015, determinó que la progresividad es un principio rector en materia de Derechos Humanos, en esto se incluyen los derechos político-electorales, estos derechos cuentan con una proyección en dos vertientes. En primer lugar, se reconoce la prohibición de regresividad, que sirve como límite a las autoridades y a las mayorías; en segundo lugar, obliga al Estado a "limitar las modificaciones -formales o interpretativas- al contenido de los derechos humanos, únicamente a aquéllas que se traduzcan en su ampliación, ya sea mediante un aumento en los alcances del derecho o en la eliminación de sus restricciones" esto también puede realizarse en aumento del reconocimiento de las personas que se consideran titulares de los mismos. (Sala Superior. Tribunal Electoral del Poder Judicial de la Federación, 2015)

El respeto al principio de progresividad es fundamental, pues implica que no es aceptable ningún tipo de retroceso en materia de cumplimiento de derechos humanos, las marchas atrás no están justificadas. Si bien, las regresiones en materia de derechos humanos no son aceptables, podría ser justificable por encontrarnos en situación de emergencia derivado de la contingencia sanitaria. No obstante, es importante ahondar en este tipo de debates para formular iniciativas desde la perspectiva de los derechos humanos. 


\section{POSIBLE COLISIÓN DE DERECHOS ANTE UNA EMERGENCIA SANITARIA Y LA REALIZACIÓN DE PROCESOS ELECTORALES}

Del apartado de antecedentes, es posible notar que el Instituto Nacional Electoral, posee entre sus atribuciones, las medidas necesarias para cumplir con su mandato constitucional, que es la organización de elecciones y continuar con el fortalecimiento del régimen de partidos políticos; esto siempre en armonía con la garantía del cumplimiento de los derechos humanos (Instituto Nacional Electoral, 2020).

Según la consideración de quienes integran el Consejo General de INE, los procesos electorales constituyen parte importante en un estado democrático, pues por medio de las elecciones se hace posible que la ciudadanía ejerza un derecho tan importante como lo es el sufragio, fundamento democrático establecido en la Constitución (Instituto Nacional Electoral, 2020).

La Junta General Ejecutiva del INE puntualizó que, en caso de conflicto con otros derechos humanos, tomando en cuenta las circunstancias excepcionales, se deben atender de manera oportuna las afectaciones por eventos imprevistos que se presenten en México, en este caso, con motivo de la pandemia por coronavirus. (Instituto Nacional Electoral, 2020).

Lo anterior podría constituir una colisión de derechos humanos, pues el derecho al voto y el derecho a la salud podrían catalogarse como de igual categoría de donde surge una contradicción lógica entre reprogramar elecciones a causa de la pandemia y preservar el buen estado de salud de la población. La autoridad administrativa se ha visto en la necesidad de realizar esta ponderación de manera temporal, pues no cuenta con garantía alguna de que, dentro de cierto plazo de tiempo, se generen condiciones que puedan seguridad en el ámbito de la salud y certeza en el desarrollo del proceso electoral. (Enciclopedia jurídica, 2020).

Las autoridades electorales nacionales han ponderado el ejercicio al derecho a la salud y al sufragio, determinando que, de no respetarse el ejercicio al derecho a la salud, puede vulnerar el bienestar de las personas involucradas en la realización de procesos electorales y esto impactar directamente en el conteo y procesamiento de votos. Estas resoluciones tomadas por el INE son la materialización de la necesidad de flexibilizar las normas electorales pues de cierta manera, han atado de manos al instituto ante situaciones de contingencia.

Existen diversos casos donde órganos jurisdiccionales han realizado fallos en situaciones de colisión de derechos humanos, tal es el caso de la Tesis VII/2014 donde el Tribunal Electoral del Poder Judicial de la Federación, dictaminó que los pueblos originarios tienen derecho a conservar sus propias costumbres e instituciones, no obstante, deben respetar el marco de los derechos humanos vigente a nivel nacional e internacional; por lo que las comunidades indígenas no pueden establecer en su derecho interno prácticas discriminatorias, pues esto es contrario al bloque de constitucionalidad. "Consecuentemente, es inconstitucional e inconvencional el sistema 
normativo indígena que vulnera algún derecho fundamental” (Sala Superior. Tribunal Electoral del Poder Judicial de la Federación, 2014).

De lo anterior, es posible notar la complejidad de ponderar un derecho frente a otro, pues el ejercicio de un derecho no puede resultar en un acto discriminatorio.

Al respecto, el Tribunal Electoral, en la Tesis XXI/2016, establece que los órganos competentes deben analizar las normas que se lleguen a cuestionar, sin hacer diferencia entre la naturaleza sustantiva o instrumental del precepto, sino mediante la lectura más favorable a la persona. De todas las lecturas posibles, se debe tomar como válida la que sea más acorde al bloque de constitucionalidad, en caso de que no sea abiertamente contraria a la constitución, debe tomarse en cuenta la que se apegue al respeto a los derechos humanos y cuando no exista "la posibilidad de que las alternativas sean directamente acordes al sistema, se deberá decretar la inaplicación" (Sala Superior. Tribunal Electoral del Poder Judicial de la Federación, 2016).

\section{ANÁLISIS DE LA SITUACIÓN DEL SISTEMA ELECTORAL EN EL DESARROLLO DE LA PANDEMIA POR COVID-19}

\section{FLEXIBILIDAD DEL MODELO MEXICANO PARA LA EMISIÓN Y CÓMPUTO DEL VOTO}

Sustancialmente México no ha cambiado la manera de votar desde hace 30 años y con cada reforma electoral, al instituto electoral se le van agregando funciones y se regulan cada vez más los procesos electorales, tanto, que, se le llegó a considerar robusto y confiable, "dotado de una importante cantidad de controles que hacen que cualquier intento de fraude sistemático masivo se pueda detectar inmediatamente y cualquier intento de fraude individual pueda ser detectado también con prontitud” (Ávila, 2012)

Actualmente, no se notan rasgos en el sistema electoral mexicano que permitan la flexibilización en la forma de votar y computar los sufragios, incluso en la sesión del 30 de junio del Instituto de Elecciones de Coahuila no son exploradas todas las alternativas para emitir el sufragio por medio de voto electrónico y tecnologías de la información.

Esta situación de emergencia sanitaria ha hecho más que evidente la necesidad de diseñar e implementar estrategias para volver más flexible la manera de votar, sacarla de su actual camisa de fuerza y modernizar los procesos electorales en beneficio de la ciudadanía mexicana. 
Colisión DE DeRechos DERIVADA DE LA PANDEMIA POR COVID-19 ANTE EL POSIBLE APLAZAMIENTo DE ELECCIONES EN MÉXICO

\section{DESCONFIANZA CIUDADANA Y TENDENCIAS CONSERVADORAS DEL MODELO ELECTORAL MEXICANO}

Uno de los retos a vencer ante el desafío de la total implementación del voto electrónico en México, además del aspecto legislativo, es la desconfianza generalizada por parte de la ciudadanía, partidos políticos e incluso cuerpos académicos, ante la posible inexistencia del voto en papel, del voto que no se podrá tocar ni verificar de manera física.

Esta desconfianza no es novedad, es un sentimiento que ha prevalecido décadas atrás y que ha resultado en procesos electorales sobre regulados que dan un grado de certidumbre frente a la mencionada desconfianza, lo anterior ha desembocado en tendencias conservadoras que se niegan a modernizar el modelo electoral mexicano.

Esto como consecuencia de la constante preocupación por la integridad de los sufragios emitidos, ya que las experiencias de años previos han mermado significativamente la confianza hacia la autoridad electoral y que han tratado de aminorar por medio de candados que fueron diseñados sin una perspectiva modernizadora en mente.

\section{PONDERACIÓN ENTRE LA CERTEZA DEL MODELO ACTUAL Y LA ACCESIBILIDAD DE UN MODELO QUE INCORPORE LA TECNOLOGÍA}

El modelo electoral actual, muy regulado y legislado, produce cierto nivel de confianza entre la ciudadanía; en primer lugar, por la posibilidad de palpar el voto en papel, y en segundo lugar porque todas las leyes que cobijan a los procesos electorales da certeza a la ciudadanía, no obstante, la solicitud de recuentos e impugnaciones.

Por su parte, la propuesta del modelo que hace más uso de herramientas tecnológicas, ciertamente requiere importantes modificaciones en materia legislativa, pero amplía opciones para la ciudadanía, además de procurar condiciones de sanidad ante el desarrollo de la pandemia.

Es importante hacer énfasis en que la esencia de la norma es la que debe establecer las bases para que los derechos humanos sean iguales, esto logrará que las medidas que se adopten en medio de una situación de emergencia sean de utilidad para garantizar su cumplimiento paritario. Por otra parte, es importante puntualizar que la incorporación de la tecnología en los procesos electorales, no constituye la panacea del problema, sino que es una herramienta que podría aportar al cumplimiento pleno de los derechos humanos.

Previo a la implementación de las urnas electrónicas o alguna variedad del voto electrónico es importante salvar diversos retos para colocar en situación de equi- 
dad a toda la ciudadanía frente a las tecnologías, por ejemplo, no todo el país tiene el mismo acceso a conectividad de internet; además que México aún tiene tareas pendientes en cuanto al derecho humanos al internet, herramienta que se considera como primordial para combatir la desigualdad (Notiese, 2011).

\section{MODELO TECNOLÓGICO Y SU IMPACTO POSITIVO ANTE POSIBLES CONTINGENCIAS SANITARIAS}

El uso de herramientas tecnológicas es imprescindible para el desarrollo de las naciones y más en la batalla contra una enfermedad con las características del COVID-19. La telemedicina, la transmisión de datos en tiempo record, internet de velocidad 5G, el GPS y el voto electrónico son temas de trascendencia en el contexto mundial, por ejemplo, Estonia desde el año 2005 hace uso del voto electrónico en sus elecciones, esta podría ser una opción para el sistema electoral mexicano pues ha ido tomando fuerza en muchos países: "se ha visto que la gente no vota necesariamente más por tener acceso a ese sistema, hay expertos que creen que esta crisis acelerará su uso" (Velert, 2020).

Con estos ejemplos, es posible hacer visible la necesidad de plantear propuestas ya a nivel legislativo para la homologación del actuar de las autoridades electorales ante el desarrollo de una crisis sanitaria como la que actualmente vivimos.

Entre las ventajas del voto electrónico se puede mencionar que facilita el proceso electoral, hace posible la identificación digital del electorado, ofrece datos fiables, el voto se puede emitir desde cualquier lugar, es verificable, reduce errores humanos, existe incremento de votantes, favorece el voto en el extranjero y los resultados electorales se obtienen en pocas horas. (Valdés, 2010)

No obstante, también podrían enumerarse varias desventajas, tales como elevados costos en el diseño inicial de los programas informáticos, en caso de no contar con los candados suficientes, pueden ser manipulados por lo que no se garantiza la secrecía del voto. El investigador Julio Valdés puntualiza que las principales limitantes del voto electrónico son las reformas legislativas que se deben aprobar y la desconfianza que provocan los medios electrónicos entre la ciudadanía.

\section{MEDIDAS LEGISLATIVAS A IMPLEMENTAR PARA GARANTIZAR EL DERECHO HUMANO AL SUFRAGIO DURANTE EL DESARROLLO DE LA PANDEMIA POR COVID-19 U OTRA POSIBLE EMERGENCIA SANITARIA}

La emergencia sanitaria que actualmente enfrenta México es muestra de la inequidad entre países con mayores y menores recursos, en primera instancia, para enfrentar a la enfermedad y, en segundo lugar, para la realización de elecciones con ayuda de la 
mejor tecnología. Esta crisis ha debilitado de manera importante a las instituciones tanto de salud, como electorales. Incluso, se ha hablado de colaboraciones entre países con mayores recursos a los países con menos para que les sea posible la realización de sus elecciones. La transición a un proceso electoral totalmente digitalizado debe ser, evidentemente gradual y constante, la situación de pandemia que vivimos lo torna impostergable.

En materia electoral, la implementación del voto electrónico en el ámbito local se ha presentado los años 20052008 y 2009 en Coahuila, donde se hizo uso de urnas electrónicas con efectos vinculantes, se considera que dieron resultados muy positivos que aportaron una experiencia en materia de comicios electorales (Valdés, 2010).

El investigador Julio Valdés menciona otras entidades federativas que han utilizado urnas electrónicas tales como Jalisco y el entonces Distrito Federal; además que órganos locales, como Baja California, Nuevo León, San Luis Potosí, Veracruz, Michoacán, Chiapas, Chihuahua, Campeche han manifestado su interés en versiones electrónicas de votación.

Instituciones como la Universidad Autónoma de México, el Instituto Politécnico Nacional o la Universidad Autónoma Metropolitana "han expresado, desarrollado o implementado esquemas o prototipos interesantes referidos al uso de la urna electrónica”. (Valdés, 2010)

Todos estos intentos o experimentos por concretar el uso de la urna electrónica se vieron en la necesidad de ser abandonados con la implementación de la reforma político electoral del 2014.

Está vastamente documentada la viabilidad de implementar el voto remoto en este país, incluso, las tendencias en los acuerdos aquí analizados se dirigen a esta conclusión, aunque sin mencionarlo. Las condiciones de emergencia sanitaria en nuestro país han hecho evidente la necesidad de explorar otras herramientas para recabar y procesar los votos, ahora los criterios son distintos, es una situación de emergencia sanitaria, donde, incluso, está en juego la preservación de vidas humanas, al evitar contagios.

Ejemplo de lo anterior, ha sido el Estado federal de Baviera donde completó la segunda vuelta de las locales en marzo, exclusivamente con voto por correo. Y es que el temor del electorado por contagiarse, no es cosa menor, en la primera vuelta de las municipales en Francia, la asistencia a las urnas fue baja, casi 20 puntos debajo de las elecciones anteriores. La segunda vuelta fue suspendida debido a que las condiciones sanitarias no eran aptas para su desarrollo. En Polonia, las normas electorales fueron modificadas para hacer uso del voto vía correo. (Velert, 2020)

La inquietud por realizar comicios electorales que no expongan el bienestar de la ciudadanía no es asunto exclusivo de la República Mexicana, sino prioridad a nivel mundial. Muchas son las experiencias en otras naciones, de cada una de ellas, 
puede detectar áreas de oportunidad a implementar en nuestro país.

Como ya se ha analizado en segmentos anteriores, es necesario proponer una actualización legislativa que contemple las siguientes modalidades de votación:

\section{Voto remoto}

Una de las modalidades del voto electrónico es el voto electrónico remoto, el cual ya ha empezado a normarse en el Instituto Nacional Electoral, principalmente para que sea efectuado el voto en el extranjero, esto con la finalidad de garantizar los derechos político electorales de la ciudadanía mexicana que reside en el extranjero.

Estos mecanismos también podrían contribuir en recabar los votos de las personas que residimos en territorio nacional; si bien, sería un proceso más complejo y la cantidad de votos harían a las elecciones más susceptibles de ser cuestionadas -el número de votos recibidos por parte de la ciudadanía residente en el extranjero no representan gran porcentaje, que pudiera definir al ganador de una elección, a diferencia de que se implementara a nivel nacional- el INE pudiese impulsar este tipo de reformas a partir escenarios similares a los que vivimos en medio de una emergencia sanitaria como la que se vive en la actualidad.

Los mecanismos de votación remota se han diseñado como un complemento del voto que se emite en las casillas, es necesario que este tipo de votación se legisle de manera exhaustiva con la finalidad de que no constituya un elemento débil en la realización de una elección pues, como ya se mencionó anteriormente, el voto en casilla brinda más confianza a la ciudadanía, pues según su percepción, reduce la posibilidad de irregularidades (Instituto Internacional para la Democracia y la Asistencia Electoral, 2020).

\section{Voto postal}

El voto postal goza en México con mayor regulación, pues es una de las estrategias por las que se recaba el sufragio de las ciudadanas y los ciudadanos residentes en el extranjero.

Corea del Sur llevó a cabo elecciones legislativas a mediados del mes de mayo del 2020, estas tuvieron una participación alta. En esas fechas, el país ya no se encontraba en cuarentena y la autoridad electoral dispuso de una legislación que permitió ofrecer a la ciudadanía la opción del voto por correo o en locales días antes de la celebración de los comicios, esto permitió controlar el número de personas que acudían a las urnas.

Otra de las estrategias implementadas por el gobierno de Corea del Sur, es que siempre se mantuvo a la población informada de las medidas de sanidad que se implementarían, todo esto respaldado por un consenso político. (Velert, 2020) 


\section{Voto adelantado}

El voto adelantado o anticipado implica brindar facilidades a los electores que no pueden presentarse en una casilla electoral el día de la jornada electoral, esto uno o varios días antes de la elección ${ }^{6}$.

Una modalidad de voto adelantado es el emitido por las mexicanas y mexicanos residentes en el extranjero, que se recibe vía postal por el INE y se computa días antes del desarrollo de la jornada electoral.

\section{REFLEXIONES FINALES}

Ante la situación de emergencia sanitaria, el gobierno mexicano se ha visto imposibilitado de cumplir a cabalidad los derechos humanos de su población, pues se han perdido empleos, vidas, patrimonios, entre muchas otras cosas. Los distintos órdenes de gobierno han optado por la preservación del estado de salud de la ciudadanía y se han pospuesto actividades no consideradas esenciales, tal es el caso de la función electoral.

Como se expuso detalladamente, con motivo de la pandemia, se ha presentado una situación sin precedentes en materia electoral, pues ha sido necesario posponer procesos electorales locales de manera indefinida, eso como resultado de la relativa efectividad del sistema electoral mexicano desde hace más de 30 años, esta percibida efectividad no ha dado motivos para hacer algún cambio sustancial. Lo anterior se ha visto confrontado en medio del desarrollo de una pandemia, esta situación extraordinaria es la que está dando pie a cuestionarse la necesidad de adoptar un modelo que haga uso de mayor tecnología.

El escenario de contingencia sanitaria obliga a cuestionar a las autoridades electorales respecto del papel de la tecnología en los múltiples espacios de la esfera pública y más aún, esta nueva realidad de cierta manera obligará a las instituciones a renovarse y ser así capaces de gestionar una transformación tecnológica de fondo que le permita alcanzar con mayor efectividad sus objetivos.

Si bien el óptimo estado de bienestar físico y psicológico de una población, debe ser prioridad para el estado mexicano, no es posible aplazar para siempre el ejercicio de un derecho humano igual de importante: participar en los procesos para elegir gobernantes y la toma de decisiones en beneficio de la ciudadanía. La modernización debe ser la nueva prioridad del sistema electoral mexicano.

Si bien la implementación de medidas sanitarias durante los procesos electorales, tales como la sana distancia o reducir el número de personas en las casillas, el

\footnotetext{
${ }^{6}$ Definición consultada en: ACE, Red de Conocimientos Electorales. Voto anticipado. http://aceproject.org/main/espanol/po/po/poa02d.htm
} 
principal reto para el sistema electoral mexicano en un contexto de emergencia por pandemia es la adopción a futuro de herramientas tecnológicas que promuevan la participación de toda la ciudadanía, por ejemplo, de las personas que viven con discapacidades. Y que, de la misma forma, contribuya a la obtención de resultados electorales certeros y confiables, ante todo velando por la salud de quienes acuden a emitir su voto.

\section{REFERENCIAS}

1. Ávila, E. (5 de julio de 2012). El sistema electoral de México es el "más confiable de América Latina". Universia.net. Recuperado el 27 de julio de 2020, de https://noticias.universia.net.mx/en-portada/noticia/2012/07/05/948550/sistema-electoral-mexi co-es-mas-confiable-america-latina.html

2. Cámara de Diputados del H. Congreso de la Unión. (2020). Constitución Política de los Estados Unidos Mexicanos. CDMX. Recuperado el 23 de julio de 2020, de http://www.diputados.gob.mx/LeyesBiblio/pdf_mov/Constitucion_Politica.pdf

3. Cámara de Diputados del H. Congreso de la Unión. (2020). Ley General de Instituciones y Procedimientos Electorales. CDMX: DOF. Recuperado el 23 de julio de 2020, de diputados.gob.mx/LeyesBiblio/pdf/LGIPE_130420.pdf

4. Carazo, P. C. (julio de 2006). El método de estudio de caso: estrategia metodológica de la investigación científica. (U. d. Colombia, Ed.) Pensamiento y gestión(20), 174. Recuperado el 28 de julio de 2020, de https://www.redalyc.org/pdf/646/64602005.pdf

5. Comisión Nacional de Derechos Humanos. (2018). Los principios de universalidad, interdependencia, indivisibilidad y progresividad de los derechos humanos. CDMX: CNDH.

6. Diario Oficial de la Federación. (2020). Acuerdo por el que se establecen acciones extraordinarias parfa atender la emergencia sanitaria generada por el virus SARS-CoV2. CDMX: DOF.

7. Enciclopedia jurídica. (2020). CDMX. Recuperado el 24 de julio de 2020, de http://www.enciclopedia-juridica.com/contenido.htm

8. Instituto Electoral de Coahuila. (2020). Sesión Ordinaria del Consejo General del 30 de junio, 2020. Video. Recuperado el 24 de julio de 2020, de https://www.youtube.com/watch?v=5wH2zgbBy4A

9. Instituto Internacional para la Democracia y la Asistencia Electoral. (2020). Elecciones y COVID-19. Estocolmo, Suecia: IDEA.

10. Instituto Nacional Electoral. (2020). Acuerdo INE/CG083/2020. CDMX: INE. 
Colisión DE DeRECHOS DERIVADA DE LA PANDEMIA POR COVID-19 ANTE EL POSIBLE APLAZAMIENTO DE EleCCiOnes EN MÉXico

\section{Instituto Nacional Electoral. (2020). Acuerdo INE/CG82/2020. CDMX: INE.}

12. Instituto Nacional Electoral. (2020). Acuerdo INE/JGE34/2020. CDMX: INE. Recuperado el 23 de julio de 2020, de https://repositoriodocumental.ine.mx/xmlui/bitstream/handle/123456789/113733/JGEex202003-17-ap-1-1.pdf

\section{Instituto Nacional Electoral. (2020). Acuerdo INE/JGE69/2020. CDMX: INE.}

14. Instituto Nacional Electoral. (2020). Coordinan INE e Instituto Estatal Electoral de Hidalgo reanudación del proceso electoral en la entidad. CDMX, México: Central Electoral-INE. Recuperado el 28 de julio de 2020, de https://centralelectoral.ine.mx/2020 /07/16/coordinan-ine-instituto-estatal-electoral-hidalgo-reanudacion-del-procesoelectoral-la-entidad/

15. Instituto Nacional Electoral. (2020). Informe que presenta la Secretaría Ejecutiva del Instituto Nacional Electoral sobre las acciones realizadas para enfrentar la pandemia del virus COVID-19. CDMX: INE.

16. Notiese. (2011). Acceso a internet: un derecho humano insatisfecho en México. CDMX: CONAPRED. Recuperado el 27 de julio de 2020, de http://www.conapred.org.mx/index.php?contenido=noticias\&id=660\&id_opcion=237\&op=448

17. Organización de los Estados Americanos. (2020). Guía para organizar elecciones en tiempos de pandemia. OEA. Recuperado el 28 de julio de 2020, de http://www.oas.org/documents/spa/press/OEA-guia-para-organizar-elecciones-en-tiempos -de-pandemia.pdf

18. Organización Mundial de la Salud. (2020). ¿Qué es una pandemia? Recuperado el Julio de 2020, de https://www.who.int/csr/disease/swineflu/frequently_asked_questi ons/pandemic/es/

19. Organización Mundial de la Salud. (2020). Preguntas y respuestas sobre la enfermedad por coronavirus (COVID-19). Recuperado el 22 de julio de 2020, de https://www.who.int/es/emergencies/diseases/novel-coronavirus-2019/advice-for-public/q-a-coronaviruses

20. Sala Superior. Tribunal Electoral del Poder Judicial de la Federación. (2014). Tesis VII/2014. CDMX: TEPJF.

21. Sala Superior. Tribunal Electoral del Poder Judicial de la Federación. (2015). Jurisprudencia 28/2015. CDMX: TEPJF.

22. Sala Superior. Tribunal Electoral del Poder Judicial de la Federación. (2016). Tesis XXI/2016. CDMX: TEPJF.

23. Secretaría de Salud y Asistencia. (2020). Informe Técnico Diario COVID-19 México. Recuperado el 22 de julio de 2020, de https://www.gob.mx/cms/uploads/attachment/file/564926/Comunicado_Tecnico_Diario_COVID-19_2020.07.21.pdf 
24. Valdés, J. T. (2010). El voto electrónico. CDMX, México: Tribunal Electoral del Poder Judicial de la Federación. Recuperado el 27 de julio de 2020, de https://www.te.gob.mx/publicaciones/sites/default/files/archivos_libros/14_voto.pdf

25. Velert, S. (2020). El dilema de que hacer con las elecciones en tiempos de Covid-19. Madrid: El País. Recuperado el 24 de julio de 2020, de https://elpais.com/internaciona1/2020-04-30/el-dilema-de-que-hacer-con-las-elecciones-en-tiempos-de-la-covid-19. html\#google_vignette 